\title{
Solvent-free aerobic oxidation of $n$-alkanes by iron(III)-substituted polyoxotungstates immobilized on SBA-15
}

Lifang Chen, ${ }^{\dagger}$ Kake Zhu, ${ }^{+} \mathrm{Li}-\mathrm{Hua} \mathrm{Bi},{ }^{+}$Andreas Suchopar, ${ }^{+}$Markus

Reicke, ${ }^{+}$Georges Mathys, ${ }^{\ddagger}$ Helge Jaensch, ${ }^{\star \prime}$ (Ulrich Kortz, ${ }^{* \prime}{ }^{+}$and Ryan M.

\section{Richards*’}

School of Engineering and Science, Jacobs University Bremen, P.O. Box 750561, 28725 Bremen, Germany and BCI Research, ExxonMobil Chemical

Europe Inc. European Technology Center, Hermeslaan 2, B-1831 Machelen, Belgium and CP R\&D, ExxonMobil Chemical Technology, Baytown

Technology \& Engineering Complex-East, 4500 Bayway Drive, Baytown, TX 77522, USA

\section{Supporting Information}

Figure S1. IR spectra of SBA-15-apts (a), the catalyst SBA-15-apts- $\mathbf{F e}_{4} \mathbf{S e}_{2} \mathbf{W}_{18}$ (b), the catalyst SBA-15-apts-Fe $\mathbf{F}_{4} \mathbf{S e}_{2} \mathbf{W}_{18}$ after reaction (c) and $\mathbf{F e}_{4} \mathbf{S e}_{2} \mathbf{W}_{\mathbf{1 8}}$ (d).

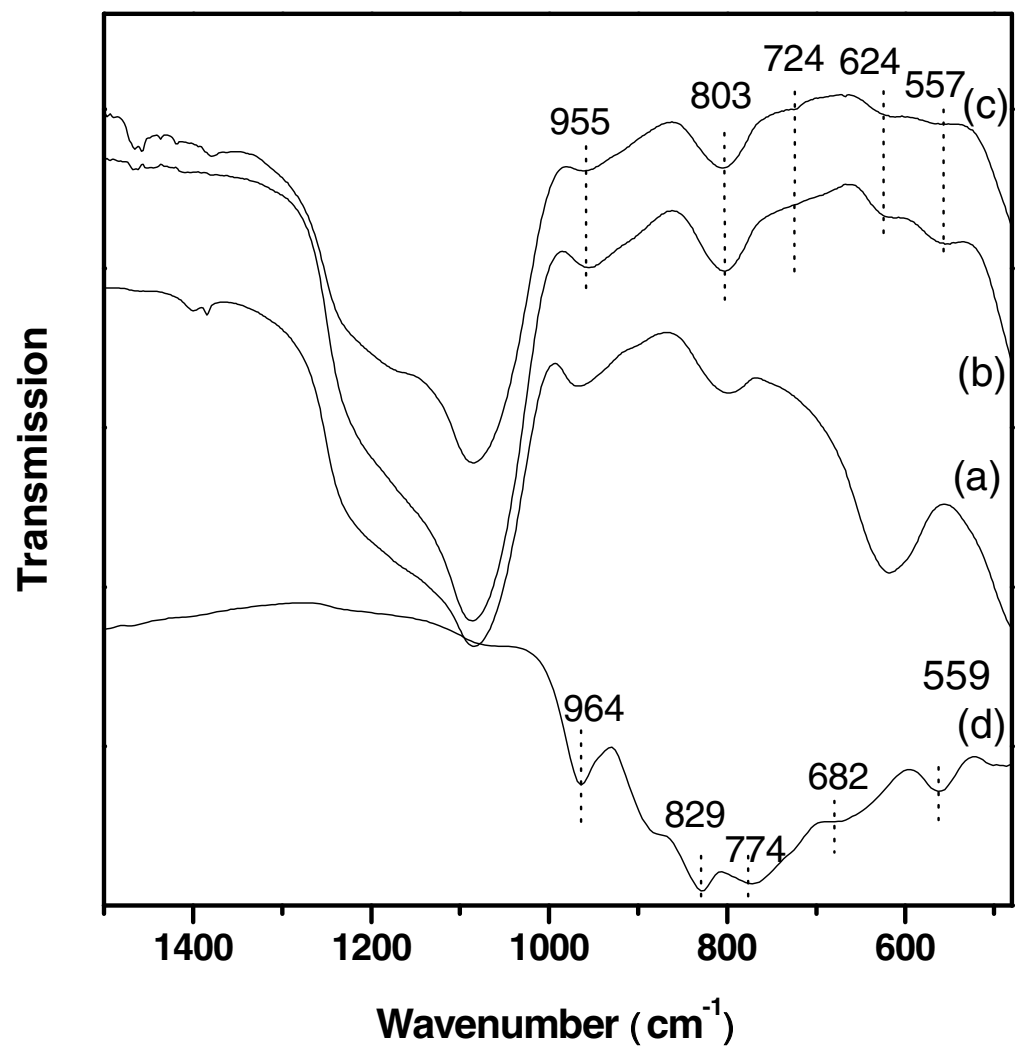


Figure S2. DRIFT spectra of SBA-15-apts (a), the catalyst SBA-15-apts-Fe $\mathbf{S e}_{\mathbf{2}} \mathbf{W}_{\mathbf{1 8}}$ (b), and the catalyst SBA-15-apts-Fe $\mathbf{S e}_{\mathbf{2}} \mathbf{W}_{\mathbf{1 8}}$ after reaction (c).

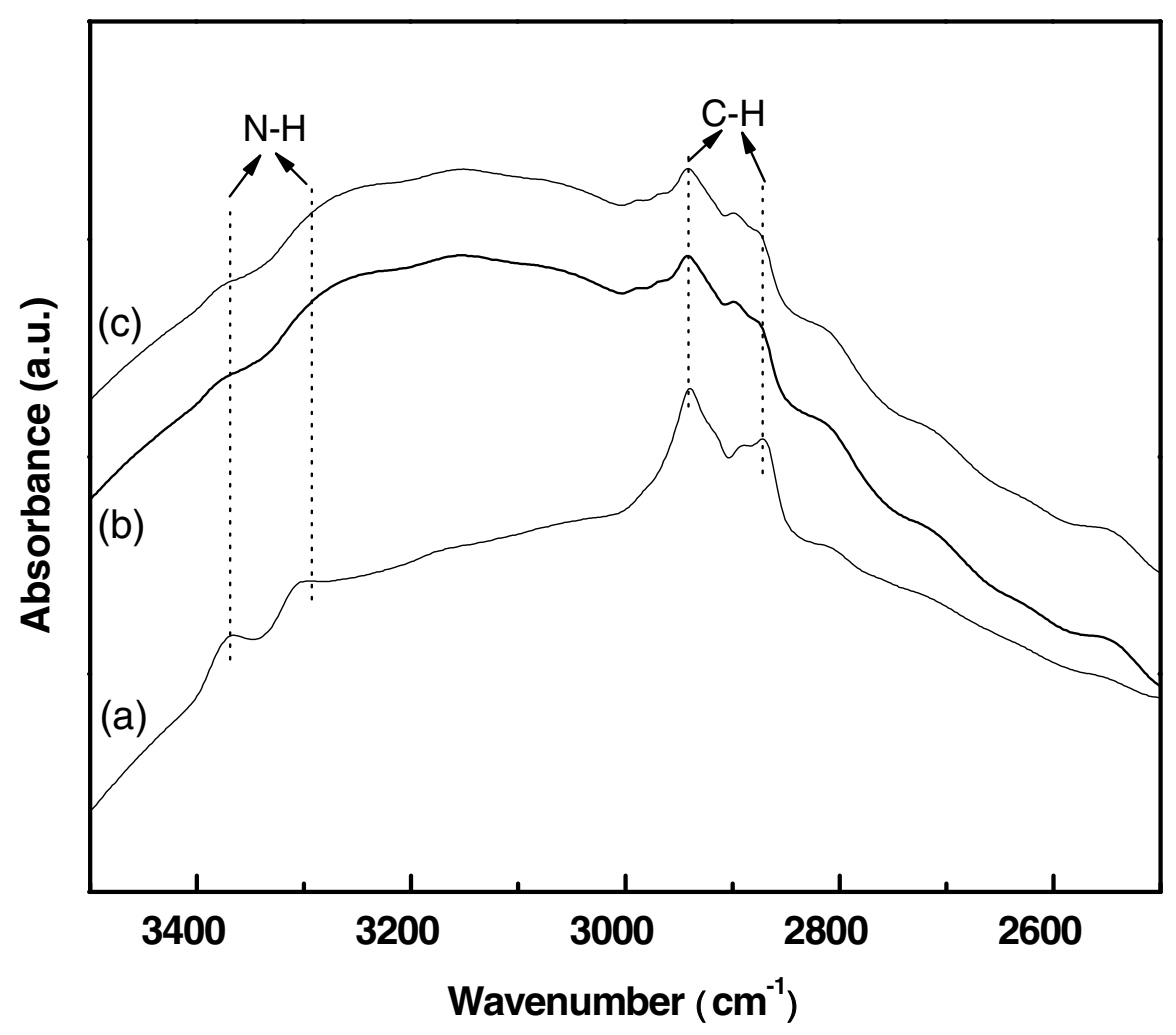

